\title{
CARBAPENEM RESISTANCE IN CLINICALLY SIGNIFICANT NON FERMENTING GRAM NEGATIVE BACILLI
}

Sevitha Bhat ${ }^{1}$, Renu Sharma ${ }^{2}$, Zenith Euphemia ${ }^{3}$

\section{HOW TO CITE THIS ARTICLE:}

Sevitha Bhat, Renu Sharma, Zenith Euphemia. "Carbapenem resistance in clinically significant non fermenting gram negative bacilli". Journal of Evolution of Medical and Dental Sciences 2013; Vol. 2, Issue 47, November 25; Page: 9131-9134.

ABSTRACT: BACKGROUND/OBJECTIVES: The growing increase in the rates of antibiotic resistance is a major cause for concern in both non-fermenting bacilli . $\beta$-lactams have been the mainstay of treatment for serious infections, and the most active of these are the carbapenems. Acquired metallo- $\beta$-lactamases (MBL) have recently emerged as one of the most worrisome resistance mechanisms owing to their capacity to hydrolyze all $\beta$-lactams, including carbapenems. We have undertaken this study to ascertain the prevalence of MBL-producing non-fermenting bacilli. MATERIALS AND METHODS: The study included 93 isolates of NFGNB from Blood, endotracheal aspirates, sputum, urine, urinary catheter tip \& pus between January 2012- January 2013. Antibiotic susceptibility to antibiotics was done by Modified Kirby Bauer method. All the isolates with a zone size $\leq 19 \mathrm{~mm}$ for imipenem were included in our study to detect the presence of MBL by ImipenemEDTA double-disc synergy test (DDST). Imipenem resistant, non MBL isolates were tested by Modified Hodge test \& Amp C $\beta$ lactamases. RESULTS: Of the 93 imipenem resistant NFGNB, 27(29.03\%) were Pseudomonas spp. ,66(70.96\%) were Acinetobacter spp.Among them, 10(37.03\%) Pseudomonas spp. and seven (10.60\%) Acinetobacter spp. were MBL positive by Imipenem EDTA double-disc synergy test (DDST). Five (8.40\%) Acinetobacter spp. were Amp C positive and one (5.88\%)strain of Pseudomonas showed positive Modified hodge test. CONCLUSION: MBL production is an important mechanism of carbapenem resistance among Pseudomonas spp. but not among Acinetobacter spp. Carbapenemases other than MBL may be responsible for carbapenem resistance in NFGNB.

KEY WORDS: Non fermenting gram negative bacilli, imipenem, metallo- $\beta$-lactamases

INTRODUCTION: The introduction of carbapenems into clinical practice represented a great advance for the treatment of serious bacterial infections caused by beta-lactam-resistant bacteria. Due to their broad spectrum of activities and stability to hydrolysis by most of the beta-lactamases, the carbapenems have been the drug of choice for the treatment of infections caused by penicillin or cephalosporin-resistant Gram-negative bacilli, especially ESBL Gram-negative infections. ${ }^{1}$ However, carbapenem resistance has been observed frequently in non-fermenting bacilli Pseudomonas aeruginosa and Acinetobacter spp. ${ }^{2}$ Resistance to carbapenem is due to decreased outer membrane permeability, increased efflux systems, alteration of penicillin-binding proteins and carbapenem hydrolyzing enzymes-carbapenemase, increased Amp C $\beta$ lactamase production.

Carbapenemases are class B metallo- $\beta$-lactamases (MBLs; IMP, VIM) or class D oxacillinases (OXA 23 to OXA 27) or class A clavulanic acid inhibitory enzymes (SME, NMC, IMI, KPC). ${ }^{3}$ Metallo- $\beta$ lactamase belongs to class $B$, which requires divalent cations of zinc as cofactors for enzyme activity. They have potent hydrolyzing activity not only against carbapenem but also against other $\beta$-lactam antibiotics. 


\section{ORIGINAL ARTICLE}

The IMP and VIM genes responsible for MBL production are horizontally transferable via plasmids and can rapidly spread to other bacteria. Modified Hodge test is a phenotypic method for detection of carbapenemases. ${ }^{5}$ The double disk synergy test has been modified using EDTA instead of a $\beta$-lactamase inhibitor. This test detects and differentiates carbapenemase and metallo- $\beta$ lactamase production from other $\beta$-lactamases. ${ }^{6}$ This study focuses on the detection of carbapenemase and metallo- $\beta$-lactamase production in imipenem resistant clinical isolates of NFGNB.

\section{AIM AND OBJECTIVES:}

- To identify, characterize and determine the antibiogram of non fermenting gram negative bacilli isolates from clinical samples.

- To determine the prevalence of carbapenemase and metallo beta lactamase producing non fermenting gram negative bacilli in this locality by phenotypic methods.

MATERIALS AND METHODS: The cross sectional study was conducted in the Department of Microbiology, Kasturba Medical College and hospital, Mangalore for a period of one year January 2012-January2013.

Specimens: The study included 93 isolates of NFGNB from Blood, endotracheal aspirates, sputum, urine, urinary catheter tip \& pus.

\section{Detailed methodology:}

Isolation and identification: The specimens were processed by standard protocols and the non fermenting Gram negative bacilli were identified by standard procedures and Vitek 2 Compact system. ${ }^{7}$

Antimicrobial susceptibility testing: All the isolates were subjected to antibiotic susceptibility testing by Kirby Bauer disk diffusion method using the following antibiotics: Amikacin $(30 \mu \mathrm{g})$, ceftazidime $(30 \mu \mathrm{g})$, cefaperazone /sulbactam $(30 \mu \mathrm{g})$, Cefepime $(30 \mu \mathrm{g})$, ceftriaxone $(30 \mu \mathrm{g})$, Cotrimoxazole $(23 \mu \mathrm{g})$. Imipenem $(10 \mu \mathrm{g})$,Piperacillin $(100 \mu \mathrm{g})$,Ticarcillin/clavulanic acid $(75 / 10 \mu \mathrm{g})$, Ciprofloxacin $(5 \mu \mathrm{g}), 8$

Control strains included:Escherichia coli ATCC 25922,Klebsiella pneumoniae ATCC 700603, Pseudomonas aeruginosa ATCC 27853.

All the isolates with a zone size $\leq 19 \mathrm{~mm}$ for imipenem were included in our study to detect the presence of MBL by Imipenem-EDTA double-disc synergy test (DDST). ${ }^{9}$

Imipenem resistant, non MBL isolates were tested by Modified Hodge test \& Amp C $\beta$ lactamases. 10,11

\section{RESULTS:}

- Of the 93 imipenem resistant NFGNB, 27(29.03\%) were Pseudomonas spp. ,66(70.96\%) were Acinetobacter spp.

- Among them, 10(37.03\%) Pseudomonas spp. and seven (10.60\%) Acinetobacter spp. were MBL positive by Imipenem EDTA double-disc synergy test (DDST).

- Five (8.40\%) Acinetobacter spp. were AmpC positive and one (5.88\%)strain of Pseudomonas showed positive Modified hodge test. 


\section{ORIGINAL ARTICLE}

DISCUSSION: Carbapenems have a broad spectrum of antibacterial activity, and these are resistant to hydrolysis by most $\beta$-lactamases including extended spectrum $\beta$-lactamases (ESBL) and AmpC $\beta$ lactamases. These are often used as a last resort in infections due to multidrug resistant Gramnegative bacilli. There has been an increase in reports of carbapenem resistance in Acinetobacter species and P. aeruginosa.

The most important mechanism of carbapenem resistance was MBL production among Pseudomonas species. Various methods have been recommended for screening MBL. These include the modified Hodge test, double-disc synergy test using imipenem and EDTA discs or ceftazidime and EDTA discs, EDTA-impregnated imipenem discs and EDTA-impregnated meropenem discs. EDTA disk synergy test is more sensitive for detecting carbapenemases. Carbapenem resistance is an emerging problem among NFGNB. The rate of MBL production in Pseudomonas spp. (37.03\%) and Acinetobacter spp. (10.06\%) in concordance with other studies. According to the previous studies, MBL production ranged from 7 to $65 \%$. 12,13

Amp C beta lactamases is found in (8.47\%)of the isolates of Acinetobacter spp. which could be important factor leading to carbapenem resistance could be an important contributory factor for meropenem resistance among the isolates in our hospital similar to other studies. Amp C $\beta$ lactamases were found in $42.85 \%$ of the resistant isolates and may contribute to the carbapenem resistance in these isolates. ${ }^{14}$

The detection of MBL and other carbapenemases is of utmost importance in deciding the most appropriate therapeutic regimen for treatment of infections.

\section{CONCLUSION:}

- MBL production is an important mechanism of carbapenem resistance among Pseudomonas spp. but not among Acinetobacter spp.

- Carbapenemases other than MBL may be responsible for carbapenem resistance in NFGNB

ACKNOWLEDGEMENT: The authors are grateful to Manipal University for providing the facilities to perform the study.

\section{REFERENCES:}

1. Gladstone $\mathrm{P}$, Rajendran $\mathrm{P}$, Brahmadathan $\mathrm{KN}$. Incidence of carbapenem resistant nonfermenting gram negative bacilli from patients with respiratory infections in the intensive care units. Indian J Med Microbiol 2005;23:189-91.

2. Varaiya A, Kulkarni M, Bhalekar P, Dogra J. Incidence of metallo-beta-lactamase-producing Pseudomonas aeruginosa in diabetes and cancer patients. Indian J Pathol Microbiol 2008;51:200-3.

3. Gupta E, Mohanty S, Sood S, Dhawan B, Das BK, Kapil A. Emerging resistance to carbapenems in a tertiary care hospital in north India. Indian J Med Res 2006;124:95-8.

4. Hemalatha V, Sekar U, Kamat V. Detection of Metallo betalactamase producing Pseudomonas aeruginosa in hospitalized patients. Indian J Med Res 2005;122:148-52.

5. Noyal M J C, AmenezesG, Harish B N, Sujtha S and Parija SC. Simple screening test for detection of carbapenemases in clinical isolates or non fermentative gram negative bacteria. Indian J med Res 2009;129:702-712. 
6. Jesudason MV, Kandathil AJ, Balaji V. Comparison of two methods to detect carbapenemase and metallo- $\beta$-lactamase production in clinical isolates. Indian J Med Res 2005;121:780-

7. Winn W Jr, Allen S, Janda W, Koneman E, Procop G, Schreckenberger P, et al., editors. In: Koneman'sColor Atlas and textbook of Diagnostic Microbiology. 6th ed. USA: Lippincott Williams and Wilkins Company; 2006. Non fermenting Gram negative bacilli; pp. 305-91.

8. Clinical and Laboratory standards institute (CLSI). Performance standards for antimicrobial susceptibility testing, 16 th informational supplements Wayne PA: CLSI Document M2-A9; 2006.

9. Yong D, Lee K, Yum JH, Shin HB, Rossolini GM, Chong Y. Imipenem-EDTA dis method for differentiation of metallo-â-lactamases producing clinical isolates of Pseudomonas spp and Acinetobacter spp. J ClinMicrobiol2002;40:3798-801.

10. Lee K, Chong Y, Shin HB, Kim YA, Yong D, Yum JH. Modified Hodge and EDTA - disk synergy tests to screen metallo- $\beta$-lactamase-producing strains of Pseudomonas and Acinetobacter species. Clin Microbiol Infect 2001; 7 : 88-91

11. Singhal S, Mathur T, Khan S, Upadhyay DJ, Chugh S, Gaind R, et al. Evaluation of methods for AmpC $\beta$-lactamase in gram negative clinical isolates from tertiary care hospitals. Indian J Med Microbiol 2005; $23: 120-4$.

12. Navneeth BV, Sridaran D, Sahay D, Belwadi M. A preliminary study of metallo-â-lactamase producing Pseudomonas aeruginosa in hospitalized patients. Indian J Med Res 2002;116:2648.

13. Gupta V, Datta P, Chander J. Prevalence of metallo-â-lactamase (MBL) producing Pseudomonas spp and Acinetobacter spp in a tertiary care hospital in India. J Infect 2006;52:311-4. Pseudomonas aeruginosa in hospitalized patients. Indian J Med Res 2002;116:264-8.

14. Sinha M, Srinivasa H. Mechanisms of resistance to carbapenems in meropenem- resistant Acinetobacter isolates from clinical samples. Indian J Med Microbiol2007;25:121-5.

\section{AUTHORS:}

1. Sevitha Bhat

2. Renu Sharma

3. Zenith Euphemia

\section{PARTICULARS OF CONTRIBUTORS:}

1. Associate Professor, Department of Microbiology, Kasturba Medical College, Mangalore.

2. MSc Student, Department of Microbiology, Kasturba Medical College, Mangalore.

3. MSc Student, Department of Microbiology, Kasturba Medical College, Mangalore.

\section{NAME ADDRESS EMAIL ID OF THE CORRESPONDING AUTHOR:}

Dr. Sevitha Bhat, Flat 102, Meadows, Mannagudda Road, Ballalbagh,Mangalore, Karnataka. Email - sevitha@rediffmail.com

Date of Submission: 05/11/2013. Date of Peer Review: 06/11/2013. Date of Acceptance: 14/11/2013. Date of Publishing: 20/11/2013 